\title{
From Principled Negotiation to Interest-based Bargaining
}

\author{
Jean-François Tremblay \\ Department of Industrial Relations, University of Quebec in Outaouais, Canada
}

Copyright $(2016$ by authors, all rights reserved. Authors agree that this article remains permanently open access under the terms of the Creative Commons Attribution License 4.0 International License

\begin{abstract}
This research paper presents a portrait both descriptive and analytical of the knowledge associated with so-called integrative bargaining methods. After justifying the choice of the term "interest-based bargaining" (IBB) to designate the different methods of integrative negotiations, an analysis of the theoretical foundations of IBB with regards to the sub-processes of the collective bargaining was done. In addition, an explanation of the theoretical premises and methodological application of IBB as described [5] was proposed. After explaining the factors that facilitate the implementation of IBB, an analysis of the results of some empirical studies on the impacts of IBB was also carried out. Finally, some reflections on the method itself, the state of knowledge on the subject as well as various avenues of research that could be considered are suggested.
\end{abstract}

Keywords Collective Bargaining, Integrative Bargaining, Interest-based Bargaining, Labor Relations

\section{Introduction}

This During the 1990s, the field of labor relations underwent significant transformations. The notorious decrease in the frequency of labor disputes constitutes probably its most visible expression. In the era of organizational changes now becoming essential with the shifting economy, different approaches to negotiation were used in a unionized environment in order to adapt the content of collective agreements to the new realities of the business environment [13].

Probably facing a union movement even more engaged and be capable of resistance, many organizations, under this new context, opted for a strategy of cooperation rather than a strategy of restriction in their adaptation [1]. This collaborative approach most often comprises a change in negotiation modes, from a discussion based on relatively strict positions, to more open bargaining based on the interests or needs of the parties whose reconciliation requires a process of problem solving. We call this mode of negotiation "interest-based bargaining" (IBB). This article proposes to analyze its conceptual foundations in order to examine its implementation, implementation difficulties and results. IBB is introduced as an interesting tool offered to participants as a means of resolving their own problems, not as a method of dissolving the conflict inherent in the employment relationship. Research shows that it improves relationships between the parties but also has implementation difficulties, especially when applied to issues of a distributive nature.

\section{What Do We Know So Far?}

\subsection{The Meaning of "Interest-based Bargaining" (IBB)}

Before getting to the heart of the matter, the use of the term interest-based negotiation (IBB) deserves an explanation that is never offered anywhere in articles or books dealing with a "cooperative" type of negotiation. Indeed, we generally (or almost generally) use as synonyms the terms interest-based negotiation, rational negotiation, integrative negotiation, win-win negotiation, specific target bargaining, to name only a few.

On a historical basis, integrative bargaining [20] was the first terminology used to describe a method inducing a cooperative negotiation approach where the interests of the parties are common or complementary [1]. According to Walton and McKersie [20], it becomes relatively simple, using a classic problem-solving process as proposed by Simon [17] (identification, research for solutions, choosing the best solution and determination of the implementation) to "integrate" the interests of the parties. But for [20],[21] integrative negotiation is not a global negotiation approach but rather a sub-process inherent to the overall process of negotiation, used when negotiating issues whose interests are common and convergent (training, health and safety, reorganization of work schedules). The term is therefore not accurate to describe the whole process given the negotiated issues and the comments of the authors who state that the negotiation is not only integrative.

It was in 1981 that the term "principled negotiation" appeared in academic and popular literature from the now famous book by Fisher and Ury [5]. It was retained in the revised edition that was published 10 years later [6]. The 
principled negotiation term specifically refers to the impact of the cooperative approach discussed in this article. But the term suffers from its subjective qualifier and implies implicitly that more traditional forms of negotiation do not appeal to protagonists' thinking. However, anyone who has worked in collective bargaining will confirm without hesitation the high degree of rationality pertaining to the strategy and tactics to be used to prepare claims, to present arguments and information, and to make the necessary compromises to get to an agreement [1], [11]. But the situation has changed and we increasingly use synonyms, which the most commonly used now is "interest-based bargaining" (IBB) [1]. Moreover, we should probably not minimize the "trends" phenomenon, which tends to favor one designation at some point and to prefer another thereafter.

It seems that the American Federal Mediation and Conciliation Service (FMCS) was the first to call IBB, the principled negotiation of Fisher and Ury [2]. The term IBB has the advantage of being more characteristic of the foundations of the method when compared to the traditional process, which is then qualified as negotiation based on positions. In this regard, the use of the term IBB is objectively limited to clarifying the basis of the negotiation, i.e. how to address the issues of negotiation, rather than implicitly predicting outcomes as do the terms "win-win negotiation" or "mutual gain bargaining" [3]. For the same reasons of objectivity and analytical rigor, we also prefer to use IBB instead of "cooperative negotiation" or "concerted negotiation ". Indeed, there is even a certain amount of cooperation and consultation in traditional bargaining. To that effect, remember that the system of collective negotiation as established by the Wagner Act in the United States implies both a convergence and a divergence of interests amongst the parties whose reconciliation passes through an interaction process involving a conflicting dynamic that can be regulated through the potential of cooperation between the parties that wish to renew the terms of their interdependence.

IBB is a negotiation approach in which the parties negotiate based on their interests and not their positions, as is the case in so-called traditional bargaining. In this type of negotiation, meeting the respective interests and maintaining a harmonious relationship between parties are equally important issues. This approach to negotiation was developed by Roger Fisher and William Ury in the early 1980s through the Harvard Negotiation Project. It became an attractive option for unions and employers wishing to establish a negotiation mechanism while supporting appeasement in their relationship. Therefore, it should not be

\footnotetext{
${ }^{1}$ Beyond the various terms used and variations in the implementation proposed by each method, we find that each has essentially the same conceptual basis, namely identification of interests and the three method principles of problem solving. Therefore, these approaches are merely methodological variations in the implementation of the basic principles of sub-processes of integrative bargaining. In this regard, the expression IBB is certainly the most appropriate to describe the negotiating method resulting from an integrative approach because it puts into perspective the first characteristic.
}

seen as a sort of far-fetched recipe that solves, or even dissolves, the conflict arising from the employment relationship. This impression that principled negotiation can be a kind of panacea is often the result of a normative and angelic presentation of this type of bargaining, or of a poor understanding of the nature of the employer-employee relationship ${ }^{2}$. For its part, our analysis aims to be objective and is exclusively limited to labor relations ${ }^{3}$.

This analysis helps to demystify this bargaining method and to understand its actual scope and effects. In order to do this, we first present a brief analysis of different processes that include collective bargaining. This allows us to better position IBB, to understand the theoretical foundations and to understand the practical applications as well as the implementation difficulties. IBB is based on relatively simple principles. When used with discretion, taking into account the reality of the particular dynamics of labor relations, it allows the parties to reach smarter agreements that take into account, at a higher degree, their respective interests.

\subsection{IBB and Its Components}

IBB as presented by Fisher and Ury [5] is based on four pillars; the first three presented here refer to debate discussions and the last to parts of the debate.

- Focus on interests and not on positions

- Imagine a wide range of solutions before making a decision. Explore solutions providing a mutual benefit.

- Resolve disputes and choose solutions based on objective criteria to which everyone agrees

- Distinctly address people issues and substantive issues

Although the four pillars are not questioned, some of the assumptions or techniques proposed by Fisher and Ury are problematic when applied to labor relations [12]. The approach presented here therefore includes a few adjustments to the original method.

\section{Focus on Interests and Not on Positions ${ }^{4}$}

This pillar of IBB is the cornerstone. If the needs, concerns, fears, desires or patterns are expressed directly, it is likely that they will be easier to meet than if their expression is reflected in the form of a position. Even if it comes necessarily from an interest or problem, it is in fact the solution that is privileged by one of the parties and not

\footnotetext{
${ }^{2}$ On the structural and contextual sources of conflict in the context of the employment relationship, see [7].

3 The method developed by Fisher and Ury [5] is adapted for application to all types of negotiation, whether commercial, diplomatic, business or labor relations. This determination to develop a universal method of application is one of the limitations of the approach of Fisher and Ury because it ignores the nature of the relationship between the parties in the complex and multidimensional universe of labor relations.

${ }^{4}$ Oddly enough, the joint desire to solve the problem is not explicitly the object one of the steps of the method as given by Fisher and Ury [5]. For the authors, the purpose of the negotiation does not seem to be an issue. However, in the context of labor relations, it is important that the parties clearly identify and define the problem or problems to solve. A lack of rigor can certainly affect the process if we consider that the problems are often complex.
} 
necessarily the most optimal, the best or the most appropriate. Additionally, the other party can recognize the relevance of interest but disagree with the proposed solution. Therefore, the source of many frustrations in collective bargaining!

The expression of an interest by means of a position stops, or at least delays direct negotiation to the satisfaction of the legitimate needs of each party. In this perspective, the basic elements of the problem that need to be solved are often obscured by the susceptibility of the negotiators to being embarrassed with regards to the position initially defended. In addition, negotiating from positions leads inevitably to negotiation, manipulation of information and the characteristic bluff of traditional negotiation no guarantee as to the validity of the deal that arises with regards to the problems experienced in the workplace.

Opposing positions often hide interests that can be reconciled. Negotiation based on interests is made using the most open communication possible whereby each party presents its interests in relation to one or more specific problems. Thus, during a first negotiation meeting, each party notifies the other of the problems that need to be discussed and the interests underlying these problems. The legitimacy of the interests of one party may not be challenged by the other party. It becomes the responsibility of both parties to find solutions that will meet their respective interests. Note that there exist convergent interests, divergent interests and different interests. They give negotiators degrees of difficulty obviously very different in terms of conflict resolution - we will come back to this later ${ }^{5 .}$ At the very least, let us remember that the underlying assumptions at this stage of the process make clear the hierarchy of need/interest/solution and that on many points it conflicts with the traditional negotiation process that rather induces a sequence of solution/interest/need.

\section{Imagine a Wide Range of Solutions, Explore Solutions of Mutual Benefit}

These are the interests that are shared and mutually acceptable to both parties that will mainly lead to the identification of solutions satisfactory for both sides and others that will eventually allow the resolution of the problem or problems. This is the crucial step of negotiation that will lead to an agreement. Often, the parties involved in IBB move quickly at this stage. They tend to think that there is only one possible solution, it being different for each party. Once this solution is identified, it becomes the privileged position and we fall back into the traditional negotiation process, each party trying to convince the other that it is the best solution.

To avoid this skidding, Fisher and Ury propose at this stage to adopt a problem-solving approach. To do this, it is important to separate the creator act from the criticism act. At first, for example, by using the brainstorming technique,

\footnotetext{
5 In addition, our experience as trainers show how IBB stakeholders sometimes have difficulty in conceptually distinguishing the concepts of interest and position.
}

parties (together) can make an inventory of possible solutions. At this phase, the only criterion is that the proposed solution takes into account the interests of both parts. Additionally, once set, the solution belongs to the group and must be separated from the person who proposed it ${ }^{6 .}$ Furthermore, it is important that all attendees be actively involved in the process. Consequently, and contrary to common practice in traditional bargaining, public speaking should not be limited to the spokesmen of the parties but rather create multiple and intersecting channels of communication where all are called to intervene heavily. Regardless of whether many of these solutions have significant deficiencies, the objective of this first phase is to identify the largest number of solutions possible. Thereafter, the most promising solutions are emphasized, that is to say those that allow the best way to satisfy the interests of the parties; and in many cases they deepen, they are transformed, they are combined and then the best are chosen. It is during this second phase that we become critics; we seek to test the solutions. In many ways, the success of this stage follows from the ability of people to participate and fully "play the brainstorm game". A third party speaker (leader or trainer) is certainly the most useful at this time.

\section{Resolving Disputes and Choosing Solutions Based on Objective Criteria}

The first criterion used to assess the accuracy of the solutions is the degree of satisfaction of the parties' interests. Thus, the solution should satisfy both employer interests and union interests identified in the first step. It is possible that for some issues it is difficult to find a solution that fully meets all expressed interests. This is often the case for issues such as wages, subcontracting or the number of days off. One should not give up too quickly on this conflict of interests because it is sometimes possible to reconcile interests that, at first sight, seem irreconcilable. For example, many employers and unions in the private sector have come to reconcile their profitability interests and employee safety by negotiating innovative provisions around work organization. Thus, at the same time, we improve profitability, jobs are preserved and we protect the purchasing power of employees.

In traditional bargaining, when it is not possible to reach an agreement on preferred solutions, one of the parties will attempt to impose its solution on another by using its balance of power. In IBB, the parties attempt to disregard this power relationship and choose instead to rely on objective criteria mutually recognized, which will be used to decide. An objective criterion can be, among others, something existing elsewhere, the opinion of an expert or a reference point of a neutral nature and perceived as such by the parties. In cases where the parties fail to find such criteria with respect to a particular issue, they may refer the matter to a third party

\footnotetext{
${ }^{6}$ During training sessions, it is always interesting to see how the employer representatives happen to generate "pro-employee" solutions and vice versa. This is certainly an indication of smooth brainstorming.
} 
who proposes the solution ${ }^{7}$. The concept of objective criteria is presented here as an alternative to the traditional balance of power. It is also important to choose solutions suggested in the previous step. Indeed, each of the chosen solutions should be evaluated and compared with equivalent criteria established by the parties. We then ask if the solution satisfies the interests of the parties. Is it a fair solution? How can we assess its fairness? Does it have side effects? What are the costs versus benefits? Does it aim at symptoms only or does it attack the real causes of the problem? Is it sustainable? Is it acceptable to members? Furthermore, evaluation through objective criteria will also explore, beforehand, the validity and appropriateness of the chosen solutions, thus reducing the risk of failure when implemented.

\section{Distinctly Address People Issues and Substantive Issues}

While other pillar issues aim at fundamental matters, we are interested in the interpersonal psychodynamic relationships that are essential to collective bargaining. Bad relationships make it difficult to identify solutions to problems that are at the center of the negotiation. They can block all process. We must find ways at the inception of the process to negotiate them, to disaggregate interpersonal conflicts, to better communicate and to promote the conservation of healthy relationships.

Collective bargaining is done by people about other people. The people negotiating have feelings, personal goals, strengths and weaknesses that mark their relationships with often complex issues. These idiosyncratic elements, even if they are sometimes very explicit, are interwoven with background issues. They may come from the history of the relationship between the parties, simple rumors, miscommunication or a lack of confidence. As important as it is to start the negotiation on the right foot, it may be appropriate, even before the first formal meeting, to hold a meeting to discuss confidence issues or interpersonal relations. It is also appropriate to hold such a meeting when, under negotiation, one party or both parties feel some "slippage" in terms of their interpersonal relationships. It should also be considered, if necessary, to replace some of the people if attitudinal problems seem unsolvable.

Problems related to interpersonal relationships come principally from miscommunication. The essential elements of good communication are well known: clarity of message, encoding that allows an unequivocal reception, listening that causes a genuine truthful decoding and feedback to confirm that the message is received [11]. However, during traditional negotiation, these elements are often dismissed for purely tactical reasons. To begin with, the position expressed is not necessarily the true objective. We ask for more than we desire and offer less than what we are willing to concede. The other party attempts to decode through the

\footnotetext{
7 Here, we ignore the concept of "BATNA" (best alternative to an agreement) proposed by Fisher and Ury. It does not seem relevant in the context of labor relations where the nature of the relationship between the parties is permanent, unlike, for example, a commercial relationship.
}

expressed position the actual position because they also know the game. It is likely they will try to avoid giving feedback that will reveal their actual position on the garbled message they have just received, and will focus throughout the discussion on the response to be provided. This intentional jamming, accented by "noise" caused by a lack of confidence or poor interpersonal relationships, makes the resolution of very complex problems very difficult. While it is possible to improve communication and interpersonal skills in traditional negotiation, some obstacles are difficult to overcome because they are inherent in the approach of negotiation and discounting tactics that arise.

\subsection{IBB and Sub-negotiation Processes}

Reference[20], in their classic work on the dynamics of collective bargaining, define the latter as a deliberate interaction of two or more complex social units which attempt to define or redefine the terms of their interdependence. The authors postulate that the parties have a variety of interests; some that are common and some that are divergent. The interaction between the parties occurs within four sub-processes which together encompass all activities related to negotiation. These processes are: distributive bargaining, integrative bargaining, attitudinal structuring and intraorganizational negotiation. It is in light of these four sub-processes that we examine the IBB.

\section{Distributive and Integrative Bargaining}

Distributive bargaining has a function of resolving disputes in respect of issues for which there is an opposition in the interests of the parties. According to this process, one's gains will be proportional to the other's losses. This will result in a zero-sum settlement. This first sub-process applies well to bargaining where union wage gains will be ripped from the assets of the company. The greater the gains are, the greater the cost will be. In this context, each of the parties seeks to maximize its earnings or its share of the total sum. Although parties have conflicting interests here, they will want to come to an agreement because of their interdependence. Alternately, information, persuasion, coercion and cooperation tactics will be used.

Integrative bargaining has the function of resolving different issues where common interests exist. Unlike distributive bargaining, it should result in gains for both parties and the benefits obtained by one will not affect the profit of the other. We will then have a variable sum negotiation where the negotiation process will seek to create value rather than simply tie. This type of trading will tend to emerge when the parties must solve a specific problem. It will then be up to the parties to find a mutually beneficial solution. Walton and McKersie divide this process into three steps: problem identification, research and evaluation of possible alternatives, classification of solutions and choice of the preferred solution.

Regardless of the negotiation approach used, we must 
recognize that there are, in labor relations, issues of distributive nature of which the interests are more difficult to reconcile. It will certainly be easier to apply IBB on integrative issues. This is why the parties will benefit from beginning with the latter in order to gain experience and to learn to negotiate from interests rather than positions. They will then have more chance of success when it comes time to discuss distributives issues ${ }^{8}$.

\section{Attitudinal Structuring}

Structuring the behaviors explains the types of relationships that can exist between parties. These types of relationships have a significant influence on the course of negotiations and are in turn influenced by it [21]. The relationship between the parties will be characterized by a series of behaviors that can be grouped under the following categories: conflict, protection against aggression, accommodation, cooperation and collusion. It is a continuum that stretches from a total confrontation within which the parties do not recognize the existential legitimacy of the other and where there is extreme distrust, to a relationship where one absorbs the other and controls it. The type of relationship that exists between the parties will the result of a series of variables, some of which are external to the relationship itself while others may be determined or influenced by the parties. As a result, the environment in which the negotiation exists, the personality of the key players, the social values of these individuals and their respective organizations, as well as their negotiations experience with each other will influence the type of relationship they will have.

Behaviors that characterize the relationship have some influence on the course of the negotiations. An attitude of cooperation may even change the perception of an issue that, at first sight is considered as a distributive issue, into a stake where the parties discover the existence of a common interest. Although the history of the relationship between the parties and the context of the negotiation contribute significantly to the shape of this relationship, it is not immutable, and can be transformed if both parties wish to do so. In this regard, the approach proposed by IBB is an interesting option, giving a central role to the quality of the relationship between parts.

\section{Intra-organizational Negotiation}

When negotiators discuss and exchange positions, they act on behalf of their respective organizations. Both before and during the negotiations, they get mandates expressing a consensus of views of the people they represent. This set of activities is called intra-organizational negotiation and is the fourth sub-process of negotiation. Most of the time, there is a consensus on the nature of the problems but differences in opinions regarding the positions and strategies. The

\footnotetext{
${ }^{8}$ However, it appears that according to the theory of [20], [21] each negotiation issue has both distributive and integrative potentials where magnitude can vary in different contexts.
}

spokesman of each party is responsible for rallying points of view. Reference [5], ignore this dimension of the negotiation as they implicitly consider each party to be a homogeneous block. The experience of collective bargaining, however, shows us how the resolution of an intra-organizational conflict plays an important role in the process and how very important negotiation efforts must often be made by the bargaining team in order to harmonize and satisfy the interests of their own constituents.

Comprehension and analysis of each of the four sub-processes and their interaction seemed essential to us to understand the scope of IBB. Thus, the mere fact of initiating negotiations with problems of a more integrative nature will lead to collaborative behaviors. Thereafter, the problems may be used by the parties in an attempt to identify the dimension of the issues which at first sight seem distributive. Once their number is minimized, a more "distributive" negotiation mode will be kept for the end. Finally, we will accord a great significance to intraorganizational negotiation. Indeed, one can change the relationship between the parties but not change the behavior of constituents. This then results in rejected agreement principles and internal crises within organizations. Furthermore, negotiating teams will need to get wider mandates with regards to the interests or problems to be solved rather than positions or requests; otherwise, it will be difficult to apply the method. IBB proposes a primarily integrative bargaining dynamic that leads the parties to develop behaviors that support accommodation and cooperation and where the resolution of intra-organizational conflict takes a different form with regards to the expectations of constituents.

\subsection{The Implementation of IBB}

The quality or effectiveness and efficiency of the process of collective bargaining can be assessed by first, measuring the degree to which the parties were able to reach their respective objectives and secondly, the resources they devoted to reaching an agreement. Given that the labor relations of the parties are interdependent and that the relationship does not end with the conclusion of an agreement, it is also important to assess the impact of bargaining on the nature and form of the relationship. In these respects, IBB appears to be an interesting alternative to the traditional method because it is expected to perform better on efficiency and effectiveness tests [13]. Even if not systematically and explicitly, several labor and management committees use IBB. The approach is relatively simple. Parties are concerned with the nature of their relationship, share their fundamental interests, real things are said and they work together creatively to find a solution mutually beneficial to both.

From the experience of unions and employers that have changed their approach to collective bargaining and the literature [4], [8], [16], [18] we have identified the factors most likely to contribute to a successful implementation of 
IBB. We have grouped them in the following table according to whether they apply before or during the negotiation.

Table 1. Factors to promote the success of IBB

\begin{tabular}{|c|c|c|}
\hline Number & Factors & Occurring \\
\hline 1. & $\begin{array}{l}\text { There is a mutual trust between the } \\
\text { parties. }\end{array}$ & $\begin{array}{c}\text { Before collective } \\
\text { bargaining }\end{array}$ \\
\hline 2. & $\begin{array}{l}\text { The parties sign an agreement } \\
\text { stipulating the details of the } \\
\text { process. }\end{array}$ & $\begin{array}{l}\text { Before collective } \\
\text { bargaining }\end{array}$ \\
\hline 3. & $\begin{array}{l}\text { Senior management of both parties } \\
\text { gives its support to the process. }\end{array}$ & $\begin{array}{c}\text { Before collective } \\
\text { bargaining }\end{array}$ \\
\hline 4. & $\begin{array}{l}\text { The negotiating teams of both } \\
\text { parties participate in a joint training } \\
\text { session on the process. }\end{array}$ & $\begin{array}{l}\text { Before collective } \\
\text { bargaining }\end{array}$ \\
\hline 5. & $\begin{array}{l}\text { Constituents of both parties are } \\
\text { aware of the new mode of } \\
\text { negotiation and its implications. }\end{array}$ & $\begin{array}{c}\text { Before collective } \\
\text { bargaining }\end{array}$ \\
\hline 6. & $\begin{array}{l}\text { Mandates obtained by constituents } \\
\text { are broad and cover interests and } \\
\text { problems, not positions. }\end{array}$ & $\begin{array}{c}\text { Before collective } \\
\text { bargaining }\end{array}$ \\
\hline 7. & $\begin{array}{l}\text { While respecting the four steps of } \\
\text { the method, it must be adapted as } \\
\text { needed. }\end{array}$ & $\begin{array}{l}\text { During collective } \\
\text { bargaining }\end{array}$ \\
\hline 8. & $\begin{array}{l}\text { Bargaining begins with issues of a } \\
\text { more integrative nature. }\end{array}$ & $\begin{array}{c}\text { During collective } \\
\text { bargaining }\end{array}$ \\
\hline 9. & $\begin{array}{l}\text { Parties shall take all the necessary } \\
\text { time to properly identify interests. } \\
\text { They will benefit from it during the } \\
\text { search for solutions. }\end{array}$ & $\begin{array}{l}\text { During collective } \\
\text { bargaining }\end{array}$ \\
\hline 10. & $\begin{array}{l}\text { To avoid skids, each party shall } \\
\text { appoint one "keeper of the method". }\end{array}$ & $\begin{array}{c}\text { During collective } \\
\text { bargaining }\end{array}$ \\
\hline 11. & $\begin{array}{l}\text { Once the parties agree on a } \\
\text { solution, they do not wait to put it } \\
\text { on paper and sign it. }\end{array}$ & $\begin{array}{l}\text { During collective } \\
\text { bargaining }\end{array}$ \\
\hline 12. & $\begin{array}{l}\text { The parties keep their constituents } \\
\text { informed throughout the process. }\end{array}$ & $\begin{array}{l}\text { During collective } \\
\text { bargaining }\end{array}$ \\
\hline
\end{tabular}

Contrary to the claims of Fisher and Ury, a minimum of trust must exist between labor and management to ensure that they benefit from IBB, without which they will quickly return to their old way of negotiation ${ }^{9}$. Also without this trust, it will be difficult to open communication and express real needs or interests. Once the decision to opt for IBB is taken, it is wise to obtain the support of the senior management of both parties and to record this support and the details that serve as parameters to the new mode of negotiation in a written agreement. This is what Cutcher-Gershenfeld $[4 \mathrm{p}$. 329] calls "the process of bargaining over how to bargain". We can refer to it as needed, thus reducing the risk of misunderstandings. In the same vein, joint training of both negotiation teams will facilitate a unique understanding of the process and the initiative that it refers to, again reducing the risk of misunderstandings. Finally, it is advantageous if there is, within each of the parties, a person who acts as guardian of the method, reminding their colleagues of the rules when required. Even better, if the parties can afford it, they would benefit from using the services of a third party if

\footnotetext{
9 To this effect, [21 p.143] spoke in these terms: "We are convinced that some minimum level of trust and support is a precondition to the integrative process. However, there is no clear evidence that a completely harmonious context is the one most productive for problem solving."
}

necessary. These recommendations will have the effect of reducing the energy spent by the parties to negotiate on how to negotiate.

The constituents must support the change in bargaining. In this regard, information sessions should be included for them. In addition, it will be important to consider that the negotiation will now be based on the interests of the parties and not positions. This implies that the mandates given by constituents will be more like a list of problems to solve rather than a book of claims or initial offers. As it is the case in traditional bargaining, the parties will ensure that their constituents are informed of the progress, thus avoiding, due to a lack of knowledge of the facts and unrealistic expectations, the rejection of an agreement in principle.

To develop collaboration and confidence between them, the parties will begin their negotiations with issues that have a larger integrative potential. As a result, they will be better equipped when faced with issues where conflicting interests appear. We will take all the time necessary to properly identify the interests of each party during the negotiation of a particular item. This will help parties identify solutions that best meet their needs and thus allow appropriate agreements.

\subsection{Results of IBB}

From a conceptual point of view [5], the use of IBB is supposed to improve the relationship between the parties because the proposed approach is largely based on the care given to the relationship between these parties. IBB is also expected to produce smarter agreements because the parties take the time to discuss openly their needs and fundamental interests in addition to basing their agreements on objective criteria.

The empirical accuracy of the first of these two assumptions, with respect to the relationship between parties, has been empirically demonstrated without a doubt [13], [3], [10]. Indeed, it is certain that a cooperative approach based on the recognition of the legitimacy of the interests of the other can only produce a better relationship in the end. This makes it easier for both parties to fully explore solutions to their problems and there is a responsive improvement in understanding of the interests and concerns of the parties. IBB also favors the establishment of permanent consultation mechanisms such as labor-management committees.

But the situation as to the accuracy of the second assumption, however, is different. Indeed, little empirical research has so far reported differences with regards to bargaining results subsequent to the use of IBB [13]. In fact, the question now is to what degree are the agreements produced with IBB different than the ones prepared following a more traditional approach to negotiation. There are several articles on case studies or complete books on IBB who worship the virtues without, however, documenting tangible results of these agreements said to be more judicious. In total we could identify only three studies dealing with the results of IBB. The first is a Quebec study including 45 
negotiators, the second is Canadian and includes a comparison of 38 companies, and the third is American and deals with 586 pairs of union-management respondents.

The study of [14] sought pairs of employers and union respondents all of whom had benefited from training on IBB and had subsequently used IBB to negotiate the renewal of their collective agreement. Over half of the survey respondents felt that IBB was appropriate to the negotiating issues such as staff turnover, hours of work and overtime distribution. However, there was a tendency to return to traditional methods when negotiating wages. Respondents of both parties are mostly of the opinion that the results were consistent with the priorities established at the outset. More particularly, positive results were obtained on movement of personnel, hours of work, overtime distribution and organizational changes. Moreover, both parties believe that the other party made gains on these issues, leading them to conclude that the results were win-win. Respondents of the survey believe that IBB produces positive results and they hope to reuse it at their next negotiations. The majority of them did not use it to negotiate wages. Although the research requirement does not allow a comparison with traditional negotiation, it still shows the positive impact of IBB.

The second study on the outcome of IBB covers 19 companies where it was used, which were compared with 19 "test" companies ${ }^{10}$ that had negotiated using traditional bargaining [15]. In all 38 cases, the old collective agreements were compared with the new ones and changes were recorded. A series of telephone interviews with stakeholders followed in order to understand the significance of the information extracted from the texts from the collective agreements of the same sector of activity. As was the case for agreements negotiated using IBB, the old agreement and the new agreement were compared to identify changes.

The comparative analysis reveals that IBB brings a greater number of changes in collective agreements. In this respect, its greatest impact is with clauses that look at the relationship between the parties and overseeing mechanisms. The analysis also shows that IBB-negotiated agreements include more union concessions than traditional conventions. Although both modes of negotiations produce basic wage increases that are comparable, IBB causes the union to make more monetary concessions on profits. In return, IBB generates a much larger number of mutual gains mainly in terms of clauses that affect the relationship between parties and its framework. This finding is quite consistent with the essence of the method that is expected to produce such agreements of mutual gains. Finally, the analysis highlights the more innovative collective agreements negotiated with the IBB. Innovations are introduced more frequently and their character is much more diverse than innovations introduced in traditional negotiation. IBB therefore favors adapting a company to a changing environment.

\footnotetext{
${ }^{10}$ The test cases, with respect to IBB cases in which each was compared, possessed similar characteristics from the point of view of size, type of labor and industry. Dates marking the negotiation period were also comparable.
}

The third study targets 586 negotiators of U.S. companies [3]. In total, $18 \%$ of the sample used IBB during their negotiations. Even though many of the users of the method were said to be satisfied, the rate was significantly more pronounced among employer representatives. However, respondents from both sides shared the view that IBB facilitates the negotiation of the functional flexibility (organization and labor distribution), of teamwork and of new forms of labor remuneration. IBB, as in other studies, also generates the establishment of joint committees of labor relations. The authors of the study conclude that IBB promotes the resolution of more complex issues related to the nature of the work but tend to lead to concessions when it comes to monetary benefits other than wages.

\section{Conclusions}

In the context of this article, we attempted to develop a comprehensive and critical analysis of IBB-associated knowledge in labor relations, both with regards to its theoretical foundations and its empirical results. Identifying different names associated with the various approaches to integrative negotiation called "cooperative", we were able to highlight the fundamental characteristics of these negotiation methods. In addition, we have established the relevance to using the term IBB to generically designate the trading method popularized by authors Fisher and Ury in the early 1980s, rational negotiation and its different variants.

Having identified and explained the nature of the four components of IBB in light of the guidance provided by the literature and our own experience as educators and researchers, we were able to analyze the method principles with respect to the behavioral theory of collective bargaining [20], [21]. From the study of the four sub-processes of collective bargaining identified by these authors, we essentially recognize that IBB is intended as a fundamentally Integrative method of trading giving importance to labeled sub-process structuring behaviors, especially with regards to the development of behaviors favoring trust, cooperation, fluency in information exchange and the contribution of all stakeholders through a process of problem solving. Moving away from the dynamic of traditional negotiation (distributive), IBB therefore seeks to bury the use of the power relationship between the parties and the tactics used to "bend" information. Some elements promoting the implementation of IBB were also identified.

A review of the literature on the results of IBB shows that generally, it achieves its first objective of improving the relationship between the parties. To this effect, the studies reviewed tend to show that the use of IBB creates a better relationship between the parties, particularly by encouraging the establishment of joint committees and greater openness to problems specific to each concerned stakeholder. As for the operating results of IBB in terms of changes in labor rules, some studies show convergence about the ability of IBB to 
generate innovations in workplaces that meet the needs of the parties and to satisfactorily amend the rules that primarily relate to work organization. The impact of IBB on negotiating wage clauses or financial impact as presented in known studies, however, remains equivocal.

While IBB appears to obtain relatively positive results and the challenges to collective bargaining that confront the parties remain numerous and complex, the method surprisingly declined in popularity in the past years [13]. Several cases are reported in which IBB was classified as "failures". Associated with the notion of failure of IBB, the inability to negotiate all issues with the method, its abandonment during the process by either party, or its inability to establish a real labor-management partnership were mentioned, among others. Through our research and our reflections on IBB, we can provide some ideas that could guide researchers and practitioners in their own assessment of the purpose of IBB in labor relations.

As a first step, we believe it is important to better understand how the method is applied in the course of actual collective bargaining and how its principles are taught. The answers to these two questions are important to better determine the relevance of the method in labor relations. A first line of investigation would be to the effect that the principles of IBB are poorly understood or implemented improperly in the process of collective bargaining. In this perspective, it is not the method itself that would be deficient but its ownership. For this purpose, although there is literature on training methods on IBB, studies on training and coaching that have as a methodological basis a non-participant observation and direct interest in understanding the principles of the method by trainers, the nature and intensity of their contribution in the various stages of the process and the rigor of implementation principles, would certainly be welcome. A second line of research would lead researchers to conduct comparative studies on the results of IBB in consideration of the terms of training and support during the process.

Moreover, the reading of [5] shows that the authors grant only two formal "virtues" to IBB; improving the relationship between the parties and producing more appropriate agreements. In this context, there should be no other expectations associated with the method. While some were able to detect in IBB the potential to enable a thorough reform of the dynamics of labor-management relations and a substantial transformation of workplaces, we believe that this is an interpretation of the theory. IBB should not be regarded as a dogma, a foolproof recipe or an end in itself, but simply as a method, a tool, a way to negotiate that potentially allows, due to its inherent logic, the achievement of the objectives of the parties. Considered here as a set of tactical means for updating a negotiation strategy of the cooperative type, IBB is subject to the same hazards as other negotiating tactics: control tactics by the negotiator, the rigor of implementation and the judicious timing of its use. Like all negotiating tactics, it contains a great potential for success, but can also easily become a complete waste of time. IBB could certainly be regarded by some as a "best" approach to negotiation because of the underlying principles (at least from an ethical perspective), but its relative efficiency results, after all, in its proper use at the negotiation table in an environment beneficial to its actualization.

For researchers, it is also important to consider the results of IBB in formulating rigorous research assumptions seeking to determine whether the parties negotiating consider, after having implemented solutions that have resulted from the process, if those were indeed wise; that is to say, if they had the actual capacity to solve the identified problem and considered it, after the fact, as wise and rational by parties involved in the process. Research in this regard would certainly be very useful.

Finally, to the extent that IBB is not an end in itself and that it constitutes a trading method fundamentally different from the traditional trading, should we be surprised that it is often abandoned along the way? In this regard, we raise these questions: Is IBB really a user-friendly method for labor relations specialists who work in a system essentially based on adversity and where the means associated with the resolution of conflicts of interest usually arises from the implementation of the domination report of each party and negotiators' skills? Under these conditions, is IBB a foreign body in a system where it could be identified as an "anomaly"? Those constituents are worried about a process for which they are confused about the whys and wherefores, thus convincing negotiators to return to the traditional confrontational approach (considered "safer"), should it be considered a failure of the method?

Reference [4] suggested that IBB not be adapted in the labor relations context and that a "mixed" model involving both the elements of the traditional and integrative negotiation would be more relevant. The frequent abandonment of IBB by parties might militate in favor of this thesis. But could the switch over of IBB to traditional bargaining during the process be not a reflection of the deficiency of the method, or a "strategic" conscious approach, but an intuitive idea on the part of some negotiators of what was already described as the optimal trading strategy by Walton and McKersie [20 p.155], namely to negotiate any integrative mode first in order "to grow the pie" for later, to appropriate the lion's share in using distributive tactics? For these authors, the integrative negotiation and implementation work of those tactics are still relatively difficult in the normal course of collective bargaining. IBB would allow establishing this mode of negotiation more easily allowing thereafter the negotiator to return, when deemed appropriate, to a more distributive type of bargaining. The challenge of the negotiator would then be not to implement more integrative tactics during the negotiation but rather "manage" the passage of integrative bargaining to distributive bargaining. But again, it does not seem to be something new under the sun insofar as already, in the 1960s, in the minds of Walton and McKersie it was viewed as one of the most 
difficult dilemmas of bargaining for a negotiator to solve.

Ultimately, we believe that regardless of the approach used, of the preferred mode of negotiation or intrinsic qualities of some developed strategies, nothing can compensate for the good faith of the parties and their genuine desire to find a solution that can be acceptable for both sides. The method that this article focuses on is, for all purposes, a method meant to help labor and management to manage the conflict that exists between them and to achieve their efficiency and equity objectives. To this effect, and regardless of the preferred mode of negotiation, we can only reiterate our confidence in the institution of collective bargaining to achieve greater justice in the workplace and to enable their devotees to thrive.

\section{REFERENCES}

[1] Barret, J. "The Interest-Based Bargaining Story at the Federal Mediation and Conciliation Service". Negotiation Journal, Vol. 31, issue 4, 2015. pp 431-435.

[2] Conry, T.W. Why aren't we getting to Yes? Mutual Gains Bargaining: Diffusion of the Theory and Practitioners' Understanding, PhD Dissertation, Ohio University, Faculty of the College of Communication. 1999.

[3] Cutcher-Gershenfeld, J., T. A. Kochan and J. Calhoun-Wells. "In Whose Interest? A First Look at National Survey Data on Interest-Based Bargaining in Labor Relation “, Industrial Relations, Vol. 40, Num. 1, 2001, pp. 1-21.

[4] Cutcher-Gershenfeld, J. "Bargaining Over How to Bargain in Labor-Management Negotiations”, Negotiation Journal, Vol. 10, Num. 4, 1994, pp. 323-335.

[5] Fisher, R. and W. Ury. Getting to Yes, Boston, Houghton Mifflin Company. 1981.

[6] Fisher, R., W. Ury and B. Patton. 1991. Getting to Yes, Revised Edition, Boston, Houghton Mifflin Company. 1991.

[7] Godard, J. Industrial Relations, The Economy and Society, Toronto, McGraw-Hill. 1994.

[8] Grant, M. and R. Paquet. “ De la négociation traditionnelle à la négociation raisonnée: implantation et maintien". Négociations en relations du travail. Presses de l'Université du Québec. 1998

[9] Hecksher, C. and L. Hall. "The Theory and Practice of Mutual Gains Bargaining", in IRRA, Proceedings of the 44th Annual Meeting, J. F. BURTON Jr ed., 1992, pp. 160-168.

[10] Kennedy, B. L. Interest-Based Collective Bargaining: A Success Story, Kingston, Queen's University, IRC Press. 1999.

[11] Lewicki, R.J. and J.A. Litterer. 1985. Negotiation, Homewood, Richard D. Irwing Inc. 1985.

[12] McCarthy, W. "The Role of Power and Principle in Getting to Yes", Negotiation Journal, Vol. 1 Num. 1, 1985, pp. 59-66.

[13] McKersie, R. B. T. Sharpe, T. A. Kochan, A. E. Eaton, G. Strauss and M. Morgensten. "Bargaining Theory Meets Interest-Based Negotiations: A Case Study. Industrial Relations. Vol. 47, no. 1, 2008, pp. 66-95

[14] Ministry of Labor. La négociation basée sur les intérêts dans le renouvellement des convention collectives : enquête auprès de négociateurs patronaux et syndicaux, Quebec, Ministère du travail, October.2002.

[15] Paquet, R. and I. Gaétan. "Does Interest-Based Bargaining Really Make a Difference in Collective Bargaining Outcomes?" Negotiation Journal, Vol. 16, no 3,2000, pp. 281-296.

[16] Shapiro, D. L. "Supplemental Joint Brainstorming: Navigating Past the Perils of Traditional Bargaining", Negotiation Journal, October, 2000, pp. 409-419.

[17] Simon, H. A. "A Behavioral Model of Rational Choice", The Quarterly Journal of Economics, Vol. 69, February, 1955, pp. 99-118.

[18] Suskind, L. A. \& E. M. Landry. "Implementing a Mutual Gains Approach to Collective Bargaining" Negotiation Journal, Vol. 7, Num. 1, 1991, pp. 5-10.

[19] Walton, R. E., J. E. Cutcher-Gershenfeld \& R. B. McKersie. Strategic Negotiations, a Theory of Change in Labor-Management Relations, Boston: Harvard Business School Press. 1994.

[20] Walton, R. E., and R. B. McKersie. A Behavioral Theory of Labor Negotiations, New York, McGraw-Hill. 1965.

[21] Walton, R. E., \& R. B. McKersie. A Behavioral Theory of Labor Negotiations ( $2^{\text {nd }}$ Edition), Ithaca, New-York, ILR Press. 1991 